\title{
Estudantes de uma escola do campo e a cultura digital
}

\begin{abstract}
Resumo: Este trabalho tem como objetivo discutir os resultados de uma pesquisa sobre a cultura digital de estudantes de uma escola do campo da rede pública municipal de Picos, Piauí. A coleta dos dados se deu por meio de um questionário aplicado a estudantes do Ensino Fundamental. Também foram usados registros em arquivo sobre a instituição. Os resultados mostraram que a maioria dos estudantes possui acesso a dispositivos eletrônicos e conexão com a internet em suas casas. É comum ficarem mais de quatro horas por dia no ciberespaço. As tecnologias digitais estão presentes nas atividades produtivas do campo, desenvolvidas por suas famílias. A escola, embora possua alguns dispositivos eletrônicos e internet, não os tem explorado suficientemente no processo de ensino-aprendizagem.
\end{abstract}

Palavras-chave: cultura digital; educação no campo; ensino fundamental.

\section{Introdução}

A discussão sobre a educação da população campesina é importante dada a parcela que esta representa no âmbito nacional, estimada em mais de 30 milhões de pessoas. (IBGE, 2010) Inclui um grupo diverso, constituído por agricultores familiares, assentados da reforma agrária, nações indígenas, povos da floresta, ribeirinhos, pescadores artesanais, quilombolas, trabalhadores assalariados rurais, dentre outros. (BRASIL, 2008) Dessa população depende a produção agropecuária e extrativista do país, além da preservação de riquezas naturais e culturais. Apesar do seu valor, a população do campo tem recebido pouca atenção no âmbito educacional. (SANTOS, 2017)

Diante disso, emergiu desde a década de 1990, com o apoio dos movimentos sociais, o debate sobre a Educação do Campo (CALDART, 2012), um paradigma educacional construído com os sujeitos do campo, em conformidade com os seus interesses e a sua realidade (MOLINA; JESUS, 2004). Fundamenta-se na ideia de complementariedade entre o campo e a cidade, na proposta de desenvolvimento para todos, e no fortalecimento da identidade campesina. (BRASIL, 2003)

Além desses fundamentos, a Educação do Campo possui princípios pedagógicos. São eles: a) ela é um direito dos povos do campo; b) o respeito às organizações sociais e o conhecimento
Alexandre Leite dos Santos Silva Universidade Federal do Piaú alexandreleite@ufpi.edu.br Gardner de Andrade Arrais Universidade Federal do Piauí gardner.arrais@gmail.com Jean Felipe Vieira Prefeitura Municipal de Picos jeanfelipevieira12@gmail.com 
por elas produzido; c) a Educação deve ser do e no campo; d) ela é produção de cultura; e) ela forma sujeitos; f) ela deve promover a formação humana para o desenvolvimento sustentável e g) o respeito às características do campo. (BRASIL, 2003) Desse modo, a Educação do Campo endossa um ensino contextualizado, com respeito aos valores, às culturas, aos saberes, às atividades laborais, aos tempos e aos espaços da população do campo.

A Educação do Campo tem respaldo na Lei de Diretrizes e Bases da Educação Nacional (BRASIL, 1996), nas Diretrizes Operacionais para a Educação Básica das Escolas do Campo (BRASIL, 2002) e nas Diretrizes Curriculares Nacionais para a Educação Básica. (BRASIL, 2013)

Paralelo à construção histórica da Educação do Campo, a população campesina tem recebido o impacto das tecnologias digitais (AFFONSO; HASHIMOTO; SANT'ANA, 2015), por meio do acesso a dispositivos eletrônicos, conexão com a internet e produtos digitais para o trabalho e gestão da produção rural.

Apesar de todos os percalços e dificuldades envolvidos na introdução das tecnologias no meio rural não há como deixar de observar que no cotidiano global os meios de comunicação tiveram um importante papel nas transformações sociais, locais, regionais e globais. As tecnologias digitais já consumiram a sociedade urbana e agora avançam mesmo que em um passo lento para o espaço rural. (BELUSSO; PONTAROLO, 2017, p. 10)

Nesse contexto, a escola do campo tem um papel importante, não apenas como espaço de inclusão digital, mas também de síntese e de crítica (LIBÂNEO, 2011) das novas relações, necessidades e identidades criadas pelo acesso a novas tecnologias. Ela também é um lugar tanto de aplicação como de proposição de políticas para o território camponês, que devem considerar o entrelaçamento entre desenvolvimento rural e tecnologias. (BELUSSO; PONTAROLO, 2017)

\footnotetext{
Um projeto de educação básica do campo tem de incorporar uma visão mais rica do conhecimento e da cultura, uma visão mais digna do campo, o que será possível se situamos a educação, o conhecimento, a ciência, a tecnologia, a cultura como direitos e as crianças e jovens, os homens e mulheres do campo como sujeitos desses direitos. (ARROYO, 2011, p. 82)
} 
Com essa perspectiva, o objetivo deste trabalho é discutir os resultados de uma pesquisa sobre a cultura digital de estudantes de uma escola do campo da rede pública municipal de Picos, Piauí. Nessa direção, uma pesquisa por artigos científicos dos últimos anos, em periódicos da área da educação, apontou três trabalhos. (BIERHALZ; FONSECA; OLIVA, 2019; LUZ; SANTOS; SANTOS, 2019; OLIVEIRA; MAURELL; COSTA, 2015)

Oliveira, Maurell e Costa (2015) realizaram uma pesquisa com alunos do campo, da Educação Infantil, na área rural de um município gaúcho. Por meio da análise de desenhos e do uso de objetos virtuais de aprendizagem, os pesquisadores inferiram que as tecnologias digitais podem facilitar o processo de aprendizagem, inclusive no contexto da alfabetização de crianças.

Luz, Santos e Santos (2019) fizeram uma investigação com estudantes do Ensino Médio de uma escola de um assentamento em um município paranaense. Os resultados obtidos por meio da aplicação de um questionário misto sobre hábitos e acesso vinculados às Tecnologias da Informação e Comunicação (TICs), sinalizaram a importância de a escola introduzi-las no processo de ensino-aprendizagem.

Em um município do Rio Grande do Sul, Bierhalz, Fonseca e Oliva (2019) estudaram por meio de questionários e análise de desenhos de 23 alunos do campo, do sétimo e oitavo ano, o uso que faziam das tecnologias no cotidiano. Apontaram com os resultados da pesquisa que a tecnologia deve ser uma das pautas da discussão sobre o projeto político pedagógico da escola do campo.

O ineditismo deste trabalho está tanto no contexto de pesquisa, na Região Nordeste, como na sua temática, em torno do seguinte problema: como os estudantes estão inseridos na cultura digital? Para tratá-1o, este texto está organizado da seguinte maneira: primeiro, expõe o que considera como cultura digital e conceitos a este vinculado, especialmente na sua relação com a escola; depois, apresenta a metodologia, seguida pelos resultados e discussões. Por fim, culmina nas considerações finais.

\section{Cultura digital e a escola}

A expressão "cultura digital" surgiu no contexto da comunicação dominada pelas tecnologias digitais (DIAS; RODRIGUES, 2019), que se referem a 
[...] um conjunto de tecnologias que permite, principalmente, a transformação de qualquer linguagem ou dado em números, isto é, em zeros e uns (0 e 1). Uma imagem, um som, um texto, ou a convergência de todos eles, que aparecem para nós na forma final da tela de um dispositivo digital na linguagem que conhecemos (imagem fixa ou em movimento, som, texto verbal), são traduzidos em números, que são lidos por dispositivos variados, que podemos chamar, genericamente, de computadores. Assim, a estrutura que está dando suporte a esta linguagem está no interior dos aparelhos e é resultado de programações que não vemos. Nesse sentido, tablets e celulares são microcomputadores. (RIBEIRO, 2014, grifo do autor)

As tecnologias digitais não apenas estão presentes no cotidiano das pessoas como têm alterado a sua cultura, quanto àquilo que fazem e produzem socialmente, inclusive a maneira de pensar e aprender. É nesse sentido que se fala em cultura digital ou cibercultura, a cultura oriunda do ciberespaço.

O ciberespaço (que também chamarei de 'rede') é o novo meio de comunicação que surge da interconexão mundial dos computadores. O termo especifica não apenas a infraestrutura material da comunicação digital, mas também o universo oceânico de informações que ela abriga, assim como os seres humanos que navegam e alimentam esse universo. Quanto ao neologismo 'cibercultura', especifica aqui o conjunto de técnicas (materiais e intelectuais), de práticas, de atitudes, de modos de pensamento e de valores que se desenvolvem juntamente com o crescimento do ciberespaço. (LÉVY, 1999, p. 17, grifo do autor)

Dessa forma, o ciberespaço refere-se tanto ao universo de informações provenientes e circulantes na web como a ampla rede de usuários que nela navega.

As relações provenientes do ciberespaço produzem a cultura digital, da "sociedade em rede". (CASTELLS, 1999, p. 5) Nesta, "o computador não é mais um centro, e sim um nó, um terminal, um componente da rede universal [...]. No limite, há apenas um único computador, mas é impossível traçar seus limites, definir seu contorno. [...] É vivo, fervilhante, inacabado: o ciberespaço em si". (LÉVY, 1999, p. 44)

A cultura digital está presente no dia a dia dos sujeitos escolares, refletindo-se na sua comunicação, relações e produções. "A escola, embora saibamos das inúmeras dificuldades enfrentadas nas redes 
públicas de ensino do país, não pode se isentar das possibilidades que a tecnologia digital proporciona". (HETKOWSKI; DIAS, 2019, p. 13) Devido às limitações estruturais e na formação dos professores e gestores escolares, é um desafio criar um diálogo entre o cotidiano escolar e a cultura digital.

Embora professores e alunos vivam em uma cultura digital, com a utilização de smartphones, redes sociais, aplicativos, jogos e os mais variados recursos que desencadeiam novos comportamentos, consideramos um descompasso entre a realidade escolar e a utilização dos instrumentos tecnológicos nos processos de aprendizagem mais interativos. Esse é o descompasso é o grande desafio da educação na contemporaneidade e na cultura digital. (HETKOWSKI; DIAS, 2019, p. 13)

Diante desse cenário, são prementes as discussões e reflexões que cercam a relação entre a escola e a cultura digital, entre desafios e possibilidades.

Segundo Pedró (2016), há três fatores que estão se globalizando e cuja combinação resultará em uma mudança pedagógica veiculada com as tecnologias digitais: a) a inserção crescente dos jovens na cultura digital, o que tem impactado nas suas formas de aprender; b) a produção e fácil acesso a tecnologias educacionais, especialmente aplicativos e conteúdos digitais gratuitos; e c) a universalização dos dispositivos de uso individual, como smartphones e tablets. Contudo, este pesquisador ressalta que uma mudança positiva causada pelas tecnologias digitais no processo de ensino-aprendizagem depende das condições em que são aplicadas e sobretudo da pedagogia adotada.

Com essa previsão, há décadas se discute qual seria o papel das escolas e dos professores. Segundo Libâneo (2011), a escola deve ser um espaço de síntese, de reflexão e de criticidade das informações veiculadas pelas tecnologias digitais. Nessa perspectiva, os professores não são substituíveis, mas são essenciais para orientar os educandos no desenvolvimento da sua autonomia e do espírito crítico. (MUNARIM, 2014) Dessa forma, a escola, especialmente por meio do papel dos educadores, deve enfrentar o avanço da tecnologia digital, problematizando (FREIRE, 2013) o seu status quo e o das informações circulantes no ciberespaço. (SELLI, 2017) 


\section{Contexto da pesquisa}

A pesquisa foi desenvolvida no ano de 2018 em uma escola da rede municipal de ensino de Picos, um município polo no sudeste piauiense. O nome da instituição não foi divulgado por motivos éticos, para preservar a sua identidade. A escola foi escolhida para a pesquisa devido à autorização do responsável pela instituição e por ser do campo. Ela se situa a uma distância de pouco mais de dez quilômetros do centro da cidade, na comunidade rural de Lagoa Comprida. Apesar da proximidade ao perímetro urbano, a escola é classificada pela Secretaria Municipal de Educação como pertencente à área rural. A maior parte do público atendido vive no campo. (BRASIL, 2010)

A escola, que possui 51 funcionários, conta apenas com as etapas do Ensino Infantil (98 matrículas) e do Ensino Fundamental (180 matrículas). Os principais meios de locomoção utilizados pela comunidade escolar são a moto e a bicicleta. Eventualmente, algumas pessoas ainda se utilizam de burros e cavalos no seu deslocamento.

Quanto à estrutura física, a escola possui seis salas de aula, sala de diretoria, laboratório de informática, cozinha, sala de leitura, banheiro interno e pátio coberto. Uma fossa recebe os resíduos do esgoto. A merenda escolar é fornecida regularmente, além de água, energia elétrica e coleta periódica do lixo. No entanto, há limitações na estrutura do prédio, como a ausência de forro no teto das salas.

Já no que diz respeito a tecnologias a escola conta com conexão com a internet e seis computadores, uma TV, um aparelho de DVD, uma antena parabólica, uma impressora, um projetor multimídia e uma câmera fotográfica, que também funciona como filmadora.

\section{Sujeitos investigados}

A pesquisa foi realizada com 12 estudantes de uma turma do sétimo ano e oito estudantes de uma turma do oitavo ano, isto é, nos anos finais do Ensino Fundamental. Os procedimentos éticos foram adotados para preservar a identidade dos envolvidos, com ciência dos seus responsáveis. Por isso, os estudantes são identificados pelo índice "E" seguido por um número.

Os estudantes possuem as características dos sujeitos enraizados social e culturalmente no ambiente de uma comunidade rural do semiárido piauiense, pois residem e trabalham na zona rural. 
Além de estudar, a maioria trabalha na agricultura ou na criação de animais para ajudar aos pais a complementar a renda do lar. Porém, as mulheres estão mais ocupadas em ajudar a suas mães, tias e avôs nos afazeres diários do lar.

A maioria (60\%) dos estudantes são do sexo feminino, na faixa etária entre 10 e 18 anos de idade, provenientes principalmente das comunidades rurais de Lagoa Comprida, Umarí, Paquetá e Beira Rio.

\section{Instrumentos de coleta de dados}

Os dados foram coletados por meio de questionários aplicados aos estudantes e dos registros em arquivos digitais sobre a escola, disponibilizados em sites institucionais.

O questionário aplicado às duas turmas continha questões abertas e fechadas. Solicitava informações gerais como idade, sexo, local de residência, ano escolar etc. além de 17 questões sobre a cultura digital. Seguem os enunciados das questões: (1) Quais dispositivos eletrônicos possui? (2) Quais locais em que normalmente acessa a internet? (3) Que tipo de conexão com a internet possui em casa? (4) Quantas horas, em média, fica conectado com a internet por dia? (5) Qual o aplicativo de comunicação para mensagens em tempo real que você utiliza com mais frequência? (6) Quais aplicativos de comunicação audiovisual que você sabe usar? (7) Assinale as suas habilidades no uso das redes sociais; (8) Quais as redes sociais em que você participa? (9) Avalie sua habilidade para procurar informações na internet; (10) Como você normalmente procede para procurar informações na internet? (11) Assinale as suas habilidades de produção com uso de tecnologias digitais; (12) Como você avalia o seu conhecimento digital, em geral? (13) Em quais atividades produtivas a sua família utiliza o apoio de novas tecnologias digitais? (14) Como as tecnologias digitais servem de apoio para as atividades produtivas rurais? (15) Na sua escola, as tecnologias digitais são utilizadas? (16) Quais tecnologias digitais são utilizadas na sua escola? (17) Na sua opinião, qual a importância das novas tecnologias digitais para o seu dia a dia?

\section{Análise dos dados}

A análise dos dados foi parcialmente estatística, por meio do software Excel, com o qual foram construídos os gráficos. 
Na análise qualitativa (LÜDKE; ANDRÉ, 2013), os dados obtidos por meio do questionário foram confrontados com os registros institucionais e inferidos com o referencial teórico adotado.

\section{Resultados e discussões}

A partir dos dados coletados, foi possível tecermos a análise e discussão dentro dos seguintes temas imbricados ao nosso problema de pesquisa: a) dispositivos eletrônicos e conexão com a internet; b) hábitos, habilidades e saberes provenientes do ciberespaço; c) a escola do campo e as tecnologias digitais; d) o cotidiano da população do campo e as tecnologias digitais.

\section{Dispositivos eletrônicos e conexão com a internet}

A discussão sobre a cultura digital dos estudantes da pesquisa começa com a descrição dos dispositivos eletrônicos por eles utilizados para o acesso ao ciberespaço. (LÉVY, 1999) Quando questionados quantos dispositivos possuem em casa, as respostas permitiram a construção da Tabela 1 .

Tabela 1 - Quantidade de dispositivos eletrônicos para acesso à internet nas residências e/ou propriedades rurais dos estudantes

\begin{tabular}{|c|c|c|c|c|c|}
\hline Estudante & Smartphone & Tablet & Notebook & $\begin{array}{c}\text { Computador } \\
\text { Desktop }\end{array}$ & Smart TV \\
\hline E01 & 4 & 0 & 1 & 0 & 0 \\
\hline E02 & 6 & 0 & 1 & 0 & 0 \\
\hline E03 & 3 & 1 & 0 & 0 & 1 \\
\hline E04 & 1 & 0 & 1 & 0 & 0 \\
\hline E05 & 4 & 0 & 1 & 0 & 0 \\
\hline E06 & 1 & 0 & 0 & 1 & 0 \\
\hline E07 & 1 & 0 & 0 & 0 & 0 \\
\hline E08 & 2 & 0 & 0 & 0 & 0 \\
\hline E09 & 1 & 0 & 0 & 1 & 0 \\
\hline E10 & 4 & 0 & 0 & 0 & 0 \\
\hline E11 & 3 & 0 & 1 & 0 & 1 \\
\hline E12 & 0 & 0 & 0 & 0 & 1 \\
\hline E13 & 4 & 0 & 0 & 0 \\
\hline
\end{tabular}




\begin{tabular}{|l|l|l|l|l|l|}
\hline $\mathrm{E} 14$ & 2 & 0 & 0 & 0 & 1 \\
\hline $\mathrm{E} 15$ & 3 & 1 & 1 & 0 & 0 \\
\hline $\mathrm{E} 16$ & 1 & 0 & 0 & 0 & 1 \\
\hline $\mathrm{E} 17$ & 1 & 1 & 0 & 1 & 0 \\
\hline $\mathrm{E} 18$ & 3 & 1 & 1 & 0 & 0 \\
\hline $\mathrm{E} 19$ & 1 & 0 & 1 & 0 & 0 \\
\hline $\mathrm{E} 20$ & 0 & 0 & 1 & 0 & 0 \\
\hline
\end{tabular}

Fonte: dados da pesquisa (2018).

Pode-se perceber a partir dos dados (Tabela 1) que o acesso ao ciberespaço se dá principalmente por meio do smartphone, embora este não seja de posse por todos os membros das suas famílias (E04, E06, E07, E09, E16, E17, E19). É comum os pais possuírem apare1hos celulares enquanto os filhos utilizam smartphones. Há casos em que este é o único dispositivo para o acesso à internet (E07, E08, E10). A maioria (95\%) dos estudantes possui o seu próprio aparelho e por meio dele acessa a internet, assim como também concluíram Bierhalz, Fonseca e Oliva (2019) na Região Sul, indo ao encontro da tendência de universalização dos dispositivos de uso individual, um dos fatores que apontam para a necessidade de uma mudança pedagógica que aproveite o potencial das novas tecnologias nos processos escolares. (PEDRÓ, 2016)

Os estudantes E12, E14 e E16 não possuem conexão com a internet em casa, embora os dois últimos a acessem diariamente. O estudante E12 é o único que não se conecta usualmente e diariamente com a internet. Assim, ainda permanece o desafio para a proposição de atividades escolares que exigem dispositivos de uso individual. Nesse caso, a rede pública ou a escola poderiam prover tais dispositivos aos que não possuem (E12), para não se trabalhar de forma excludente.

Há muitas possibilidades para o desenvolvimento de atividades escolares com o uso do smartphone e de outros dispositivos móveis, especialmente no trabalho com áudios, vídeos, simuladores, infográficos, imagens, calculadora, pesquisas, dentre outros.

Quando questionados sobre os locais em que normalmente acessam a internet, a maioria (85\%) respondeu que acessa em sua própria casa. Há também os que acessam na casa de parentes (55\%) e de amigos (50\%) e em locais públicos (40\%), como lojas, lanchonetes e restaurantes. 
Concernente ao tempo diário de utilização da internet, as respostas levaram à construção do gráfico (Figura 1) a seguir.

Figura 1 - Respostas* dos estudantes sobre o tempo diário de utilização da internet

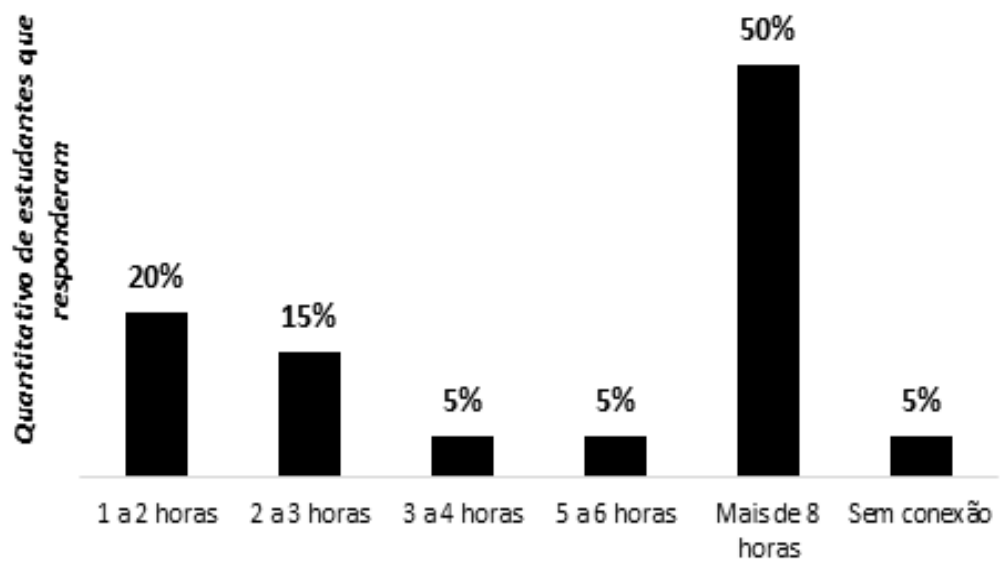

Tempo diário de utilização da internet

Fonte: dados da pesquisa (2018).

Pode-se constatar a partir da Figura 1 que a maioria dos estudantes dedica mais de quatro horas por dia do seu tempo em atividades no ciberespaço, mesmo considerando as limitações de dispositivos eletrônicos disponíveis em seus lares. Metade dos sujeitos investigados declarou ficar mais de oito horas por dia no ciberespaço. Dessa forma, é evidente que há uma cultura digital muito forte em meio às práticas e saberes (LÉVY, 1999) compartilhados pelos jovens do campo. Deve-se superar a visão de que toda área rural é um local idílico, isolado e distante da dinâmica e do acesso aos dados globais veiculados por meio da web. Os estudantes do campo estão também sujeitos aos impactos positivos e negativos (ZANCAN; TONO, 2018) do acesso às tecnologias digitais.

A maioria dos sujeitos da pesquisa utiliza redes sociais para se comunicar, como indica a Figura 2. 


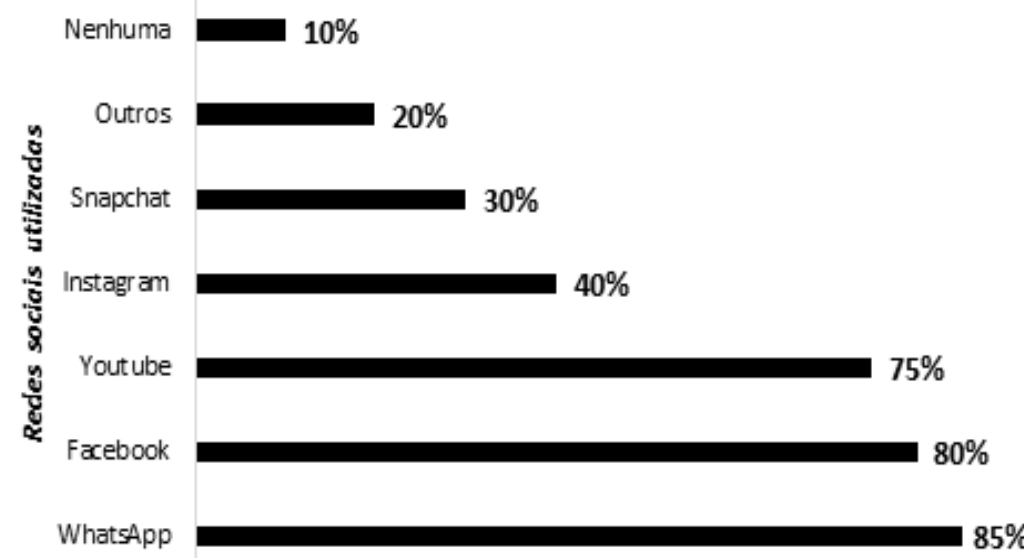

\section{Quantitativo de estudantes que responderam}

Fonte: dados da pesquisa (2018)

A incorporação das tecnologias pelos estudantes para usos sociais e comunicação os predispõe para a participação em atividades escolares que as usem. (PEDRÓ, 2016) Para isso há um leque de possibilidades envolvendo o correio eletrônico, jogos, softwares, sites, blogs, livros abertos, histórias em quadrinhos, scratch etc.

Os dados obtidos mostram que estes estudantes usam as redes sociais para receber e enviar mensagens de texto (85\% pelo WhatsApp e 35\% pelo Messenger do Facebook) e chamadas de vídeo (80\% pelo WhatsApp e 50\% pelo Facebook). Além disso, nas redes sociais saberes são aprendidos e experenciados, pois 35\% sabem enviar arquivos de textos, enquanto 80\% arquivos de imagens, 65\% links de páginas da web, 75\% arquivos de vídeo e 60\% arquivos de áudio. Dessa forma, estão imergidos na cultura digital "caracterizada pela presença das mídias, pela mudança de comportamentos, pela celeridade das informações e pela tele prontidão do tempo e espaço". (HETKOWSKI; DIAS, 2019, p. 17; LÉVY, 1999)

Os sujeitos declararam também ter adquirido outras habilidades (saber fazer) por meio do uso de dispositivos eletrônicos e em meio ao ciberespaço, como editar fotos (95\%), editar textos (80\%), criar e editar vídeos (75\%), gravar e editar arquivos de áudio (70\%), criar e editar imagens (60\%), jogar jogos digitais (60\%), criar blogs (25\%), criar e postar páginas web (20\%), criar sites (20\%), criar jogos digitais (20\%) e criar bancos de dados (5\%). 
Os saberes e práticas dos estudantes que emergem da cultura digital não são bem explorados no ambiente escolar, assim como constatou Pedró (2016, p. 19) em um contexto global.

Em todo o mundo, os esforços realizados nas últimas décadas para transformar o ensino e a aprendizagem parecem não dar frutos, porque continuamos tendo uma escola muito parecida com a que tínhamos 20 anos atrás, quando a internet começou a se tornar popular. Em 20 anos, as tecnologias digitais realizaram grandes progressos que alteraram, muitas vezes radicalmente, nossa vida, desde o trabalho até a vida cotidiana. E parece que a escola está escapando dessa transformação. Realmente, são muitas as pesquisas e os dados que sugerem uma relativa resistência à mudança dos sistemas escolares.

Quando questionados se as tecnologias digitais são utilizadas na escola, obteve-se o seguinte resultado (Figura 3).

Figura 3 - Respostas* dos estudantes quanto a se a escola utiliza as tecnologias digitais

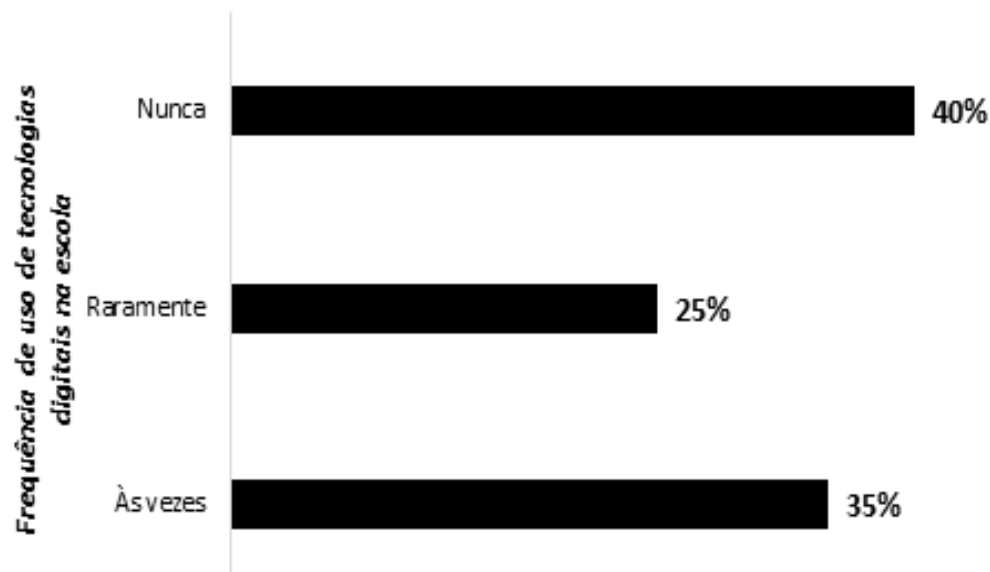

Quantitativo de estudantes que responderam

Fonte:dados da pesquisa (2018).

Assim, segundo mais de 50\% dos sujeitos da pesquisa, a escola utiliza às vezes ou raramente as tecnologias digitais, sendo predominantes o uso do projetor de slides e da televisão. Nenhum estudante marcou as opções de respostas "sempre" ou "frequentemente". 
Portanto, é possível inferir que os estudantes estão inseridos na cultura digital, mas a sua escola não. A escola possui conexão com a internet, computadores e outros dispositivos digitais, que não são disponibilizados para os estudantes.

Há, assim, um descompasso entre a escola e a realidade dos estudantes (HETKOWSKI; DIAS, 2019), indicando a necessidade de investimentos em tecnologias digitais naquela, não apenas no aspecto físico, mas também em recursos humanos.

Para tanto, faz-se necessário que as políticas públicas para a Educação do Campo favoreçam a ampliação das tecnologias para os povos dessa diversidade, para que se possa avançar no conhecimento e acesso às informações, cultura e serviços que antes não se era possível, uma vez que a maioria vive fora dos centros urbanos. A tecnologia utilizada de forma correta pode a favorecer a interação, a comunicação e o aprendizado dos sujeitos. Nessa perspectiva, a escola possui papel fundamental na transmissão do conhecimento, uma vez que em muitos casos o local de maior acesso as TIC's pelos educandos é o ambiente escolar. (LUZ; SANTOS; SANTOS, 2019, p. 16)

Dado isso, os estudantes ainda não dimensionam as possibilidades do uso das tecnologias digitais na vida escolar. Quando questionados sobre qual a importância das novas tecnologias para o seu dia a dia, relativamente poucos (35\%) relacionaram com as atividades escolares. Seguem alguns excertos:

É importante para eu me comunicar com as pessoas de longe, jogar online, usar minhas redes sociais; também gosto de decifrar códigos etc. (E09, Questionário, 2018).

Para jogar, mexer em aplicativos e entrar nas redes sociais. (E11, Questionário, 2018).

É importante para diversão e informação. (E14, Questionário, 2018).

Para fazer pesquisas, trabalhos da escola, noticias e para se conectar com pessoas que moram em outros lugares. (E18, Questionário, 2018). 
A maioria, como ilustrado pelos estudantes supracitados, relacionou com as redes sociais (80\%) e com a obtenção de notícias e informações (60\%).

\begin{abstract}
A escola ainda carrega diversos traços tradicionais, muitas vezes fora da contextualização da realidade que envolve o sujeito, ao acarretar num desinteresse por parte dos alunos, que dão mais atenção ao entretenimento à tecnologia que lhe é oferecida. Por isso, a escola deve estar preparada para que ocorra uma reformulação do sistema no sentido de atualização e adequação, para a formação das crianças e jovens, também no âmbito tecnológico (LUZ; SANTOS; SANTOS, 2019, p. 7).
\end{abstract}

A escola poderia se aproximar da realidade dos estudantes do campo por meio do uso das novas tecnologias, já que a cultura digital e a cultura camponesa estão entremeadas. Seria um espaço para a promoção da síntese cultural (FREIRE, 2013), com criticidade, problematizando as informações, as notícias e a realidade. (LIBÂNEO, 2011; MUNARIM, 2014; SELLI, 2017)

A inserção das tecnologias digitais na escola não altera de per si a qualidade da educação, porque esta depende também da pedagogia adotada e das condições em que elas são aplicadas em sala de aula, especialmente do papel dos professores (PEDRÓ, 2016). No entanto, a presença e uso adequado na escola das tecnologias digitais, como um elemento cultural do cotidiano dos estudantes, pode levá-los a valorizá-la e a aproximá-la deles.

Ao não se levar em consideração o estabelecimento das novas relações sociais que surgem com o acesso a novas tecnologias estamos na verdade criando uma escola desarticulada da sociedade, numa perspectiva de apenas consumir informação sem produzi-la e sem refletir crítica e coletivamente sobre os próprios saberes. Propor uma lógica de vínculo entre o território camponês e outros por meio das tecnologias valoriza as instituições educacionais como espaço de produção e compartilhamentos de saberes. (BELUSSO; PONTAROLO, 2017, p. 11)

Os princípios da Educação do Campo sinalizam para um ensino que respeite os modos de vida e leve em conta a realidade dos alunos do campo. (BRASIL, 2003)

Um dos traços fundamentais que vem desenhando a identidade deste movimento por uma educação do campo é a luta do povo 
do campo por políticas públicas que garantam o seu direito à educação e a uma educação que seja no e do campo. No: o povo tem o direito de ser educado no lugar onde vive; Do: o povo tem o direito a uma educação pensada desde o seu lugar e com a sua participação, vinculada à sua cultura e às suas necessidades humanas e sociais. (CALDART, 2011, p. 149, 150)

O vínculo com as necessidades da população camponesa inclui reconhecer o papel das tecnologias digitais no seu cotidiano. E, se bem empregadas, elas podem expandir os horizontes de aprendizagem. (PEDRÓ, 2016)

\section{O cotidiano da população do campo e as tecnologias digitais}

Este estudo tem demonstrado que a realidade dos estudantes do campo não exclui as tecnologias digitais. Ao serem questionados quais atividades produtivas rurais exercidas por suas famílias que utilizam tecnologias digitais, eles responderam conforme aponta a Figura 4.

Figura 4 - Respostas* dos estudantes sobre atividades produtivas rurais de suas famílias que demandam o uso de tecnologias digitais

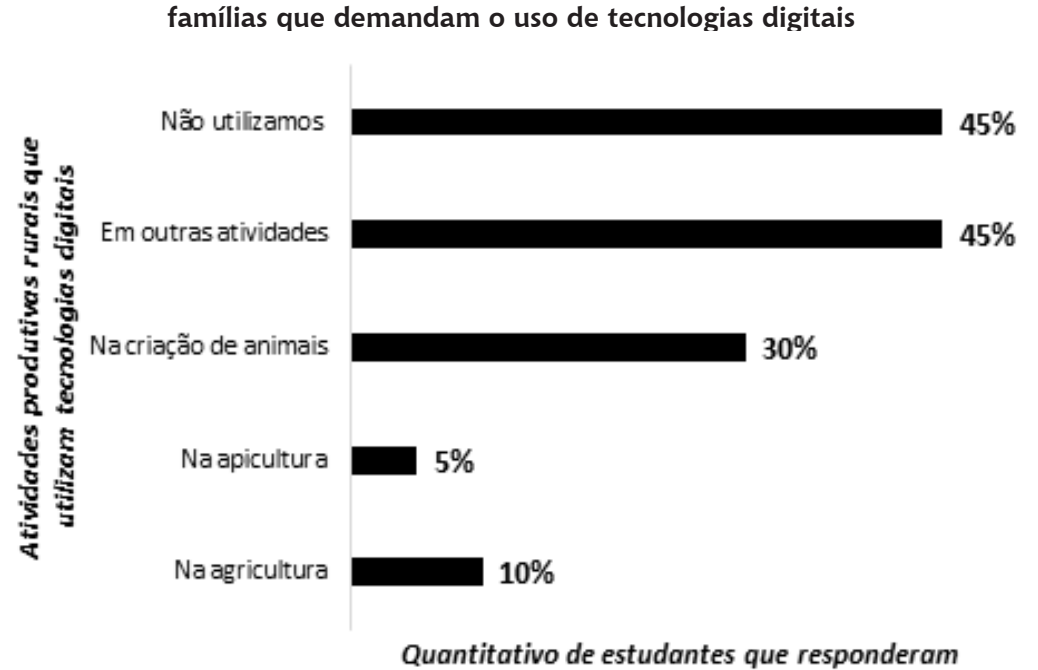

Quantitativo de estudantes que responderam
* Cada estudante poderia marcar mais de uma alternativa

Fonte: dados da pesquisa (2018). 
que suas famílias utilizam tecnologias digitais nas atividades de criação de animais, apicultura e agricultura. Não foi explicado quais seriam as "outras atividades" produtivas rurais que demandam o uso dessas tecnologias (na região pratica-se também o extrativismo vegetal e o artesanato), mas de que modos específicos elas têm contribuído para o trabalho rural (Figura 5).

Figura 5 - Respostas dos estudantes sobre as contribuições das tecnologias digitais para as atividades rurais de suas famílias

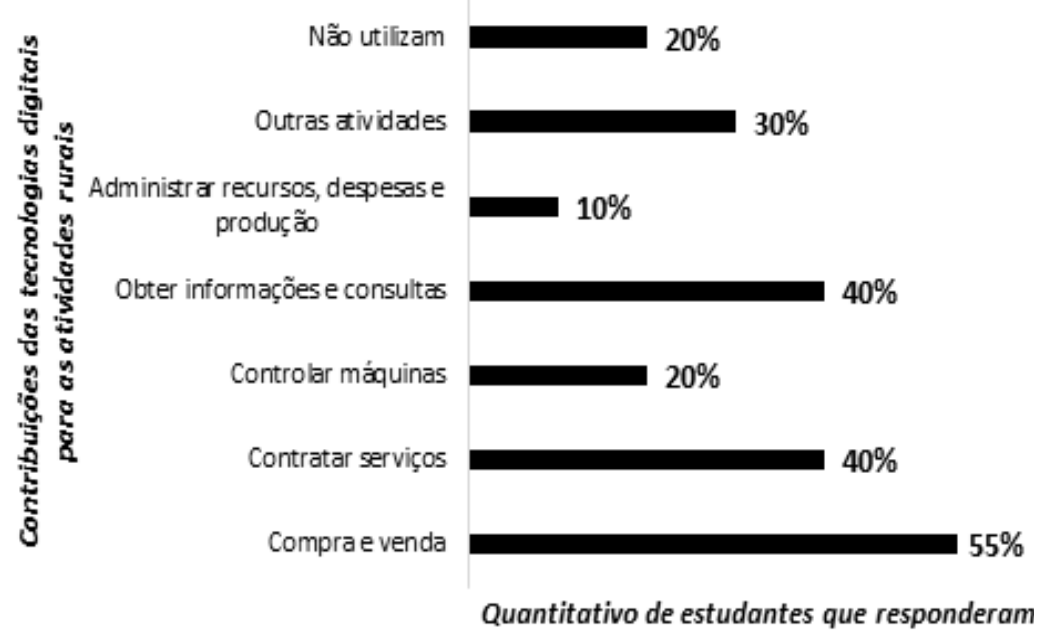

Fonte: dados da pesquisa (2018).

Desse modo, as tecnologias digitais estão presentes no cotidiano dos agricultores familiares (AFFONSO; HASHIMOTO; SANT'ANA, 2015), auxiliando-os principalmente na compra e venda de produtos, na contratação de serviços e como fonte de obtenção de informações e consultas. "É notória a importância das tecnologias de informação em melhorar as atividades no campo, pois ela proporciona qualidade e oportunidade por meio de artefatos que promovem e fidelizam o conceito da sustentabilidade". (ZARPELON et al., 2015) Se exploradas desde a escola por meio de projetos de aprendizagem que englobem toda a comunidade (SILVA, 2009), é possível que contribuam mais ainda para as famílias dos estudantes do campo. 


\section{Considerações finais}

Este trabalho procurou investigar como os estudantes de uma escola do campo de Picos, Piauí, estão inseridos na cultura digital ou cibercultura. Os resultados mostraram que a maioria deles possui acesso a dispositivos eletrônicos e conexão com a internet em suas casas. É comum ficarem mais de quatro horas por dia no ciberespaço, especialmente nas redes sociais; e nelas têm compartilhado saberes e desenvolvido diversas habilidades no aspecto comunicacional. As tecnologias digitais estão presentes nas atividades produtivas do campo, desenvolvidas por suas famílias.

A escola, embora possua alguns dispositivos eletrônicos e internet, não tem os explorado suficientemente no processo de ensino-aprendizagem. Há um descompasso entre a escola e os estudantes quanto à relação com a cultura digital.

No contexto da pesquisa em Educação do Campo, este trabatho sinaliza para a necessidade de se aprofundar as discussões e as reflexões sobre a inserção da população camponesa na cultura digital e sobre os desafios e possibilidades disso nas escolas do campo. Um fenômeno global é que tem sido crescente o ingresso dos jovens na cultura digital e isso inclui os das áreas rurais, como indicam os resultados.

As políticas públicas para as escolas do campo, assim como para as escolas urbanas, precisam levar em conta a influência das tecnologias digitais nos hábitos e nos modos de aprender dos estudantes, para efeitos de investimentos em infraestrutura, aquisição de recursos didáticos e formação dos profissionais da educação. Deve-se pensar em como reduzir o descompasso entre os estudantes e as escolas quanto à inserção na cultura digital. Ao mesmo tempo, a escola deve se constituir em um espaço de síntese e de criticidade.

É muito importante o papel dos professores do campo diante do cenário criado pelas tecnologias digitais. Os estudantes necessitam de orientação para desenvolver um espírito reflexivo e problematizador em meio ao oceano de informações que correm no ciberespaço, que engloba um número crescente de sujeitos do campo, especialmente os jovens.

\section{Students from a rural school and digital culture}

Abstract: This paper aims to discuss the results of a survey about digital culture of students at a rural middle school from Piauí, Brazil. Data collection 
took place through a questionnaire applied to students. Archived records about the institution were also used. The results showed that most students have access to electronic devices and an internet connection in their homes. It is common to spend more than four hours a day in cyberspace. Digital technologies are present in the rural productive activities, developed by their families. The school, although it has some electronic devices and internet, has not explored them sufficiently in the teaching-learning process.

Key-words: digital culture; rural education; middle school.

\section{Estudiantes en una escuela de campo y cultura digital}

Resumen: Este documento tiene como objetivo analizar los resultados de una investigación sobre la cultura digital de los estudiantes de una escuela rural do Piauí, Brasil. La recolección de datos se realizó a través de un cuestionario aplicado a estudiantes de la educación primaria. También se utilizaron registros archivados sobre la institución. Los resultados mostraron que la mayoría de los estudiantes tienen acceso a dispositivos electrónicos y a una conexión a internet en sus hogares. Es común pasar más de cuatro horas al día en el ciberespacio. Las tecnologías digitales están presentes en las actividades productivas rurales, desarrolladas por sus familias. La escuela, aunque tiene algunos dispositivos electrónicos e internet, no los ha explorado suficiente en el proceso de enseñanza-aprendizaje.

Palabras clave: cultura digital; educación rural; educación primaria.

\section{Referências}

AFFONSO; E. P.; HASHIMOTO, C. T.; SANT'ANA, R. C. G. Uso de tecnologia da informação na agricultura familiar: planilha para gestão de insumos. Biblos, Rio Grande, n. 60, p. 45-54, 2015. https://doi. org/10.5195/biblios.2015.221.

ARROYO, M. G. A educação básica e o movimento social do campo. In: ARROYO, M. G.; CALDART, R. S.; MOLINA, M. C. (org.). Por uma educação do campo. 5. ed. Petrópolis: Vozes, 2011. p. 65-86.

BELUSSO, A.; PONTAROLO, E. Uma reflexão sobre tecnologia digital nas escolas do campo como possibilidade para o desenvolvimento dos territórios camponeses. In: SEMINÁRIO INTERNACIONAL SOBRE DESENVOLVIMENTO REGIONAL, 8, 2017. Anais [...] Santa Cruz do Sul: UNISC, 2017.

BIERHALZ, C. D. K.; FONSECA, E. M.; OLIVA, I. Concepções dos estudantes de uma escola do campo sobre tecnologia. Revista Brasileira de Educação do Campo, Tocantinópolis, v. 4, e3297, 2019. http://dx.doi.org/10.20873/uft.rbec.v4e3297. 
BRASIL. Decreto-Lei $n^{\circ}$ 7352, de 4 de novembro de 2010. Dispõe sobre a política de educação do campo e o Programa Nacional de Educação na Reforma Agrária. Brasília, DF, 2010.

BRASIL. Diretrizes curriculares nacionais gerais da educação básica. Brasília, DF: MEC: SEB: DICEI, 2013.

BRASIL. Ministério de Educação e Cultura. Lei no 9394, de 20 de dezembro de 1996. Estabelece as diretrizes e bases da Educação Nacional. Brasília, DF, 1996.

BRASIL. Ministério da Educação e Cultura. Conselho Nacional de Educação. Comissão de Educação Básica. Resolução $n^{0}$ 01, de 03 de abril de 2002. Estabelece as diretrizes para a Educação Básica nas escolas do campo. Brasília, DF, 2002.

BRASIL. Ministério da Educação e Cultura. Grupo Permanente de Trabalho de Educação do Campo. Referências para uma política nacional de Educação do Campo. Caderno de Subsídios, Brasília, DF, 2003.

BRASIL. Ministério da Educação e Cultura. Conselho Nacional de Educação. Comissão de Educação Básica. Resolução $n^{\circ}$ 02, de 28 de abril de 2008. Estabelece diretrizes complementares, normas e princípios para o desenvolvimento de políticas públicas de atendimento da Educação Básica do Campo. Brasília, DF, 2008. Disponível em: http://portal.mec.gov.br/ arquivos/pdf/resolucao_2.pdf. Acesso em: 6 set. 2014.

CALDART, R. S. Por uma educação do campo: traços de uma identidade em construção. In: ARROYO, M. G.; CALDART, R. S.; MOLINA, M. C. (org.). Por uma educação do campo. 5. ed. Petrópolis: Vozes, 2011. p. 147-160.

CALDART, R. S. Educação do campo. In: CALDART, R. S. et al. (org.). Dicionário da Educação do Campo. 2. ed. São Paulo: Escola Politécnica de Saúde Joaquim Venâncio; Rio de Janeiro: Expressão Popular, 2012, p. 257-265.

CASTELLS, M. Sociedade em rede. Tradução de Roneide Venâncio Majer. São Paulo: Paz e Terra, 1999. v. 1.

DIAS, V. C.; RODRIGUES, I. A. N. Relações pedagógicas em tempos de cultura digital: novos modos de aprender e ensinar. SCIAS Educação, Comunicação e Tecnologia, Belo Horizonte, v. 1, n. 1, p. 39-61, 2019. Disponível em: http://200.198.28.135/index.php/SCIASEdcomtec/ article/viewFile/3525/2181. Acesso em: 11 maio 2020.

FREIRE, P. Pedagogia do oprimido. 54. ed. Rio de Janeiro: Paz e Terra, 2013.

HETKOWSKI, T. M.; DIAS, J. M. Educação, cultura digital e espaços formativos. Plurais, Salvador, v. 4, n. 2, p. 11-25, 2019. http://dx.doi. org/10.29378/plurais.2447-9373.2019.v4.n2.11-25. 
IBGE. População nos Censos Demográficos, segundo as Grandes Regiões, as Unidades da Federação e a situação do domicílio 1960/2010. Sinopse do Censo Demográfico 2010. Disponível em: https:// censo2010.ibge.gov.br/sinopse/index.php?dados = 8. Acesso em: 10 maio 2020.

LÉVY, P. Cibercultura. Tradução Carlos Irineu da Costa. São Paulo: Editora 34, 1999.

LIBÂNEO, J. C. Adeus professor, adeus professora? Novas exigências educacionais e profissão docente. 13. ed. São Paulo: Cortez, 2011.

LÜDKE, M.; ANDRÉ, M. E. D. A. Pesquisa em educação: abordagens qualitativas. 2. ed. Rio de Janeiro: E.P.U., 2013.

LUZ, F. C. O. C. A.; SANTOS, S. A.; SANTOS, E. M. Uso das TICs por educandos do Ensino Médio de escolas do campo. Revista Brasileira de Educação do Campo, Tocantinópolis, v. 4, e5407, 2019. http://dx.doi. org/10.20873/uft.rbec.v4e5407.

MOLINA, M. C.; JESUS, S. M. S. A. (org.). Contribuições para a construção de um projeto de educação do campo. Brasília, DF: Articulação Nacional "Por uma Educação do Campo", 2004. (Coleção Por uma Educação do Campo, v. 5).

MUNARIM, I. As tecnologias digitais nas escolas do campo: contextos, desafios e possibilidades. 2014. Tese (Doutorado em Educação) Universidade Federal de Santa Catarina, Florianópolis, 2014.

OLIVEIRA, D. C. P.; MAURELL, J. R. P.; COSTA, C. A. S. Potencializando as práticas pedagógicas em uma escola do campo: a contribuição das tecnologias digitais. Revista Atlante: Cuadernos de Educación y Desarrollo, Málaga, 2015. Disponível em: ww.eumed.net/rev/ atlante/2015/07/pedagogia.html. Acesso em: 11 maio 2020.

PEDRÓ, F. Educação, tecnologia e avaliação: por um uso pedagógico efetivo da tecnologia em sala de aula. In: GONÇALVES, M. T. et al. (coord.). Experiências avaliativas de tecnologias digitais na educação. São Paulo: Fundação Telefônica VIVO: UNESCO, 2016. p. 19-34. Disponível em: http://fundacaotelefonica.org.br/wp-content/uploads/pdfs/ experiencias_avaliativas_portugues.pdf. Acesso em: 23 abr. 2020.

RIBEIRO, A. E. F. Tecnologia digital. In: FRADE, I. C. A. S.; VAL, M. G. C.; BREGUNCI, M. G. C. (org.). Glossário CEALE*. Termos de alfabetização, leitura e escrita para educadores. Centro de Alfabetização, Leitura e Escrita CEALE. Belo Horizonte: Faculdade de Educação da UFMG,2014. 
SANTOS, R. B. História da Educação do Campo no Brasil: o protagonismo dos movimentos sociais. Teias, Rio de Janeiro, v. 18, n. 51, p. 210-224, 2017. https://doi.org/10.12957/teias.2017.24758.

SELLI, M. S. Reverberações de uma metodologia dialógica em experimentações com tecnologias digitais de uma escola de educação do campo. 2017. Tese (Doutorado em Informática na Educação) Universidade Federal do Rio Grande do Sul, Porto Alegre, 2017.

SILVA, M. P. M. A construção do conhecimento, as intervenções metodológicas e os novos saberes e fazeres na cultura digital. 2009. Tese (Doutorado em Informática na Educação) - Universidade Federal do Rio Grande do Sul, Porto Alegre, 2009.

ZANCAN, C. R. B.; TONO, C. C. P. Hábitos dos adolescentes quanto ao uso de mídias digitais. EDUCA Revista Multidisciptinar em Educação, Porto Velho, v. 5, n. 11, p. 98-119, 2018. https://doi.org/10.26568/2359-2087.2018.2647.

ZARPELON, M. C. et al. Tecnologias digitais: promovendo o desenvolvimento sustentável para o jovem do campo. REGET Revista do Centro de Ciências Naturais e Exatas, Santa Maria, v. 19, n. 1, p. 64-70, 2015. http://dx.doi.org/10.5902/2236117015435.

Submetido em 07/06/2020.

Aceito em 22/04/2021. 